\title{
A Comparative Study on Reflective Thinking in Various EFL Contexts
}

\author{
Akin GURBUZ \\ Gaziantep University, School of Foreign Languages
}

\begin{abstract}
Reflective thinking is described as active, persistent, and careful consideration of any belief or supposed form of knowledge in the light of the grounds that support it and the further conclusion to which it tends (Dewey, 1993). In this respect, the present study focuses on EFL teachers' reflective thinking skills at different institutions (primary, secondary and university). The study further investigates the issue in terms of genders and experience differences. To measure four major constructs of reflective thinking: (a) ability to selfassess, (b) awareness of how one learns and (c) developing lifelong learning skills and (d) belief about self and self-efficacy, a Reflective Thinking Questionnaire (Choy \& Oo, 2012) has been conducted to fifty teachers from different institutions. In addition to the questionnaire, a semi-structured interview has been carried out with six participant teachers through email exchange to explore the issue in depth and enhance the reliability of the questionnaire. Although the study suggested no statistically significant disparity for institutional differences, it presented a significant difference between male and female teachers in terms of reflective thinking on their teaching practices.
\end{abstract}

Keywords: Reflective thinking, self-assess, life-long learning, self-efficacy, teacher education.

\section{Introduction}

In one of his studies, Zeichner (2010) summarizes the recent changes and developments in teacher education as a shift from a focus on training teachers to perform certain behaviors, to more fully educating teachers, to understand the reasons and rationales associated with different practices and with developing teachers' capacities to make intelligent decisions about how to act based on their carefully developed educational goals, on the contexts in which they were working, and on the learning needs of their students. Richards \& Lochkart (1996) assert that although language teaching has traditionally been described in terms of what teachers do, that is the actions and behaviors which teachers carry out in the classroom and the effects of these on learners, it involves also such multidimensional tasks as cognitive, affective and behavioral tasks. They further clam that what teachers do is a reflection of what they know and believe, and that teacher knowledge and teacher thinking provide the underlying framework or schema which guides the teacher's classroom actions.

Freeman (2002) places reflective practice into the central pillar of teacher education supposing that their mental lives are storied or narrative webs of past and present experience and their knowledge is reflective of their position in the activity of teaching. Borg (2003) states that teachers have cognition about all aspects of their works. The extent to which teachers can implement instruction corresponding with their cognitions is substantially determined by teacher cognitions and practices on a part informing and contextual factors. (Tabachnick \& Zeichner 1986 cited in Zeichner, 1990).

According to Lucas \& Tan (2006) there is an increasing emphasis on the need for reflection as an integral part of learning to learn within the undergraduate education of teachers. It is expected from students to reflect as a part of their subject-based studies, but also to reflect on their learning and development of skills, for example, through the maintenance of a personal development portfolio. When they graduate and enter professional and managerial life, they are supposed to act as reflective practitioners and to exercise professional judgment. The primary concern of this study is to investigate the utilization of reflective thinking by teachers practicing with different age groups at various institutions (primary, secondary and university education) in Turkey. To pursue the following research questions the reflective teaching questionnaire Choy \& Oo (2012), the topics of which were created based on a study by Hamilton (2005) on the development of reflective thinking, was used and a semi-structured interview conducted: 
(a) Do the teachers teaching at various institutions show significant difference in terms of reflective thinking?

(b) Is there a significance of reflective thinking in terms of gender difference?

(c) Does teaching experience play a significant role in reflective thinking?

\section{Literature Review}

Teacher's education has been into a transition phase since the 1970s' first realization of teacher's mental lives or as Freeman (2002) delineated as the hidden side of the work. Further, Borg (2003), defines a broader umbrella term for teacher belief and teacher perception terms as teacher cognition. Summarizing the studies carried out on in-service teacher cognitions, he comments on the diversity of the work and how it is based on different conceptual frameworks and states that these cognitions might be influenced by internal and external factors, as a relationship between teachers' cognitions and their practices (2006, pp. 106-107).

In the preface of their Reflective Teaching in Second language Classrooms books (Richards \& Lockhart, 1996), Richards asserts that recently there has been a movement away from methods and other external or top down views of teaching toward an approach that seeks to understand teaching in its own terms in second language teaching. The instructors themselves and their actual teaching processes are the focus of such an approach and it seeks to gain a better understanding of these processes by exploring with teachers what they do and why they do it. Richards further claims that the result is the construction of an internal or bottom up view of teaching. The approach is often teacher initiated and directed because it involves instructors observing themselves, collecting data about their own classrooms and their roles within them, and using that data as a basis for self-evaluation, for change, and hence for professional growth.

Reflection is defined as careful consideration or thought by Minott (2009); a process of disciplined intellectual criticism combining research; knowledge of context, and balanced judgment (critical thinking) about previous, present, and future actions, events or decisions. In light of this, reflective teaching is an approach to teaching, learning and problem solving that uses reflection as the main tool. As Bengtsson (1993) outlines, it encourages teachers to create distance between themselves and their practice. Martin Jr. Wood \& Stevens (1988) further claim that teachers are themselves involved in analyzing, discussing, evaluating, changing and developing their practices, by espousing an analytical approach to their work.

According to Boody (2008), teacher reflection can generally be characterized through the observation of past, problem-solving, critical analysis and putting thoughts into action. Therefore, the theoretical framework of the present study has been an integration of Boody (2008), Hamilton (2005) and Schon (1987) and the characteristics of reflective thinking have been based on a) reflection as retrospective analysis, $b$ ) reflection as problem solving, c) critical reflection of self, and d) reflection on beliefs about self and self-efficacy. The ability to self-assess takes reflection as a skill to think over prior experiences and use them as an impact on current practices. This retrospective analysis also includes the ability to self-assess. Boody (2008) describes reflection as taking necessary steps to analyze and articulate problems before taking action, which allows for a more constructive action. He further asserts that:

"...critical reflection can be thought of as the process of analyzing, reconsidering and questioning experiences within a broad context of issues like ethical practices, learning theories and use of technologies" (Boody, 2008, p.502).

According to Williams and Burden (1997 in Choy \& Oo, 2012), teachers are highly influenced by their beliefs, which are closely linked to their values and these beliefs are found to be more effective than knowledge in influencing how individuals organize tasks and problems and are better predictors of how teachers behaved in the classroom (Pajares, 1992). Another important factor that determines the reflective practices of teachers is self-efficacy, which can also determine the effectiveness of teaching as an intrinsic motivation (Markley et al, 2009).

\section{Methodology}

The research questions led us to the use of both the interpretive approach as well as statistical analysis of the data obtained in order to provide richer answers to the research questions unpinning this study. In the 
interpretive approach, the individual constructs personal meaning when they grapple with the environment around them to make it meaningful (Radnor, 2002), implying the need for an in depth and insightful analysis of data. Statistical analysis was used in our attempt to get a more generalized understanding of the data obtained and to look for general trends (Cohen et al, 2000) among the participants.

A questionnaire with a Likert-scale was used to collect data in this study. The questionnaire consists of 33 questions where 50 teachers were asked to rate on a scale of $1-5$ (1=strongly disagree and $5=$ strongly agree). The topics for the questionnaire were created by Choy \& Oo (2012) based on research by Hamilton (2005) on the development of reflective thinking. The statements cover four major areas of development: (a) ability to selfexpress, (b) awareness of how one learns and (c) developing lifelong learning skills and (d) belief about self and self-efficacy. Each of the four areas of development was further broken down into sub-sections as observing own performance, using feedback and evidence, finding and analyzing patterns, making judgments, concepts and misconceptions, knowledge construction, metacognition, developing identity as a learner, transferring learning to other contexts, learning as a lifelong process, and developing a personal belief system. The questionnaire was piloted on 10 volunteers and unclear statements were adjusted by Choy \& Oo (2012) in their study.

In addition to the questionnaire, a semi-structured interview was conducted to 6 teachers through open ended questions via e-mail exchange. The open ended questions for the semi-structured interview were based on the sub-topics on the questionnaire. The interview was conducted to analyze the data obtained by the questionnaire for an in depth and insightful analysis.

\section{Data Analysis and Findings}

Analysis of the data was done using SPSS Statistics 22 for descriptive results of the questionnaires, and the semi-structured interviews were analyzed in terms of themes. A One-Way ANOVA test was used to analyze the institutional and years of experience differences; and an Independent-Samples T Test was used to analyze gender differences on responses to the questionnaire. The questionnaires were further analyzed in terms of frequency of responses to each of the 1-5 scale on the questionnaire.

Of all the participants, $40 \%$ work as instructors at university, $30 \%$ work as teachers at secondary and $30 \%$ work at primary school. Table 1 presents descriptive analysis of institutional differences among teachers. From the table it can be seen that there is no scientifically significant difference among institutional differences $(\mathrm{p}=0.31>0.05)$, so it can be assumed that teacher working at different stages of education with different age groups reflect on their teaching practices and themselves in a similar way.

TABLE I: Institutional Differences

\begin{tabular}{l|lllll}
\hline Institutions & $\boldsymbol{\%}$ & $\mathbf{M}$ & SD & SEM & $\boldsymbol{P}$ \\
\hline Primary & 30 & 3,92 & 9,86 & 2.55 & \\
Secondary & 30 & 4,06 & 10.37 & 2.68 & 0.31 \\
University & 40 & 3,93 & 9.32 & 1.77 & \\
\hline
\end{tabular}

Table 2 introduces descriptive results for experience years of teachers as a whole. It can clearly be observed that $10 \%$ of the participants have 1-3 years of experience, $36 \%$ have $4-6$ years of experience, $16 \%$ have $7-9$ nine years of experience, $38 \%$ have ten or more years of experience and there is no scientifically significant differences in reflective thinking in terms of experience $(\mathrm{p}=0.11>0.05)$.

TABLE II: Experience

\begin{tabular}{l|lllll}
\hline Experience & $\boldsymbol{\%}$ & M & SD & SEM & $\boldsymbol{P}$ \\
\hline 1-3 years & 10 & 4.03 & 10.44 & 4.67 & \\
4-6 years & 36 & 3.85 & 8.30 & 1.96 & \\
7-9 years & 16 & 3.93 & 8.52 & 3.01 & 0.11 \\
10 or more years & 38 & 4.07 & 9.51 & 2.18 & \\
\hline
\end{tabular}

An independent-samples t-test was conducted to compare male and female participants' responses on reflective thinking questionnaire. The participants consisted of $\% 56$ male teachers and $44 \%$ female teachers. Table 3 indicates that there is a scientifically significant difference in males' $(M=3.88, S D=8.29)$ and females' $(\mathrm{M}=4.08, \mathrm{SD}=9.42)$ responses; $\mathrm{t}(48)=-2.60, \mathrm{p}=0.01$. These results suggest that females' reflective thinking scores are higher males'. 
TABLE III: Gender Differences

\begin{tabular}{l|cccccc}
\hline Experience & $\boldsymbol{\%}$ & $\mathbf{M}$ & SD & SEM & T-value & $\boldsymbol{P}$ \\
\hline Male & 56 & 3.88 & 8.29 & 1.57 & & 0.01 \\
Female & 44 & 4.08 & 9.42 & 2.01 & -2.60 & $*$ \\
\hline
\end{tabular}

The data collected through questionnaires were further analyzed in terms of four major areas of development: (a) ability to self-express, (b) awareness of how one learns and (c) developing lifelong learning skills and (d) belief about self and self-efficacy in percentage. A one-way ANOVA test was analyze institutional differences for each theme on the questionnaire. Table 4 points out that there is only a scientifically significant difference in life-long learning skills of participant groups $(\mathrm{p}=0.03<0.05)$. These results indicate that primary, secondary and university teachers reflect on life-long learning skills differently. On the other hand, there can be observed no other scientifically significant difference among each group of institution in terms of ability to selfasses, awareness of how to learn and beliefs about self and self-reflection.

The results obtained from the questionnaires are further analyzed for teachers from each institution and their responses on four major themes. Only the responses with a rating of 4 (agree) or 5 (strongly agree) have been discussed. A similar analysis was conducted by Choy\&Oo (2012) for categorized levels of items on the questionnaire as: introductory, intermediate and advanced. Such a categorization for each item have been neglected in the study, but a categorization for each theme has been piloted and the results are given below.

TABLE IV: Institutional Differences on Themes

\begin{tabular}{l|l|c|llll}
\hline Themes & Groups & \% & M & SD & SEM & $\boldsymbol{P}$ \\
\hline \multirow{2}{*}{ Ability to } & Primary & 21.33 & 3.93 & 4.20 & 1.08 & \\
Self-Assess & Secondary & 20.83 & 3.86 & 3.27 & 0.84 & 0.72 \\
& University & 28.50 & 3.85 & 4.09 & 0.92 & \\
\hline \multirow{2}{*}{ Awareness of how } & Primary & 17.11 & 3.51 & 3.98 & 1.03 & \\
one learns & Secondary & 18.67 & 3.59 & 3.22 & 0.83 & 0.51 \\
& University & 25.25 & 3.46 & 2.14 & 0.48 & \\
\hline \multirow{2}{*}{ Life-long learning } & Primary & 18.00 & 3.72 & 3.80 & 0.98 & \multirow{2}{*}{ skills } \\
& Secondary & 22.89 & 4.06 & 4.61 & 1.19 & \multirow{2}{*}{$* 0.03$} \\
\hline \multirow{2}{*}{ Belief about self } & University & 26.89 & 3.73 & 2.44 & 0.55 & \\
and self-efficacy & Primary & 18.00 & 3.80 & 2.06 & 0.53 & \multirow{2}{*}{0.62} \\
& Secondary & 17.33 & 3.76 & 2.28 & 0.59 & \\
\hline
\end{tabular}

The results on the table indicate that all the teachers from each institution have responded changeably on each theme. While the averages for ability to self-assess and and awareness of how one learns are close to each, a significant difference can be observed in terms of life-long learning skills and belief about self and selfefficacy. The primary school teachers either agreed or strongly agreed on life-long learning skills with an average of $63.70 \%$ and instructors at university rated closely with an average of 67.22 ; however, secondary school teachers rated significantly higher than the former groups with an average of $76.30 \%$. On the other hand, a significant difference can also be observed on the item on belief about self and self-efficacy, too. While the primary school teachers rated this item either agree or strongly agree with 68.89 , the secondary school teachers rated with only 57.78, and the instructors at university rated considerably higher with an average of $83.33 \%$. From the results it can be indicated that although the rates for responses on each theme is changeable for all the institutional groups, a significant difference can be seen for the life-long learning skills and belief about self and self-efficacy. While the secondary school teachers rated the former theme highest and the instructors rated the latter theme highest.

TABLE V: Institutional Differences on Themes in Percentage

\begin{tabular}{l|ccc}
\hline Themes/ Groups & $\begin{array}{c}\text { Primary } \\
\mathbf{\%}\end{array}$ & $\begin{array}{c}\text { Secondary } \\
\mathbf{\%}\end{array}$ & $\begin{array}{c}\text { University } \\
\mathbf{\%}\end{array}$ \\
\hline Ability to self-assess & 74.44 & 69.44 & 71.25 \\
Awareness of how one learns & 60.00 & 62.22 & 56.11 \\
Life-long learning skills & 63.70 & 76.30 & 67.22 \\
Belief about self and self-efficacy & 68.89 & 57.78 & 83.33 \\
\hline
\end{tabular}

Table 6 shows the descriptive results in percentage for gender differences in terms of four major themes on the questionnaire. Only the responses with a rating of 4 (agree) or 5 (strongly agree) have been discussed. The results clearly indicate that there is a significant difference between male and female participants of the study on 
all the themes. These results are compatible with the results obtained from the independent-samples T-test on SPSS statistics.

TABLE VI: Gender Differences on Themes in Percentage

\begin{tabular}{l|cc}
\hline Themes/ Groups & $\begin{array}{c}\text { Male } \\
\text { \% }\end{array}$ & $\begin{array}{c}\text { Female } \\
\text { \% }\end{array}$ \\
\hline Ability to self-assess & 68.16 & 76.14 \\
Awareness of how one learns & 54.76 & 64.65 \\
Life-long learning skills & 67.46 & 70.71 \\
Belief about self and self-efficacy & 65.48 & 78.79 \\
\hline
\end{tabular}

The last of the qualitative data analysis was piloted on experience differences of the participant teachers for major themes on the questionnaire. In general, there is no significant difference among teachers with various experience years. The most significant difference can be seen on beliefs about self and self-efficacy item for which teachers with 1-3 years of experience rated the highest agree/strongly agree, an average of $86.67 \%$ while the closest was rated 7.5\% lower by those 7-9 years of experience, an average of $79.17 \%$. It can be concluded that teachers in first years of experience rated slightly higher on reflective thinking in general, but there is no significant difference among the teachers as a whole.

TABLE VII: Descriptive results for experience differences on themes in percentage

\begin{tabular}{l|cccc}
\hline Themes/ Groups & $\mathbf{1 - 3}$ years & 4-6 years & 7-9 years & 10/over \\
& & & & \\
& $\%$ & $\%$ & $\%$ & $\%$ \\
\hline Ability to self-assess & 70.00 & 73.15 & 71.88 & 70.61 \\
Awareness of how one learns & 64.44 & 57.41 & 52.78 & 62.00 \\
Life-long learning skills & 71.11 & 66.04 & 58.33 & 75.44 \\
Belief about self and self-efficacy & 86.67 & 68.52 & 79.17 & 66.67 \\
\hline
\end{tabular}

In addition to the quantitative analysis of the questionnaires, a qualitative analysis was conducted through a semi-structured interview based on four major themes on the questionnaire. The interview form was shared with 6 participant teachers via email exchange and their responses on each theme have been analyzed.

From the interview with teachers, it can be concluded that the teachers value the feedback from their students and they observe students' and their own performances during the class. By the feedback from the learners, the teachers are able to reflect on themselves and as Markley et al (2009) indicate, teachers attain an intrinsic motivation to be a good educators. Ball (2009) further notes that when teachers gain self-efficacy, they have high metacognitive awareness of themselves and they can change the strategies they are using to attain their intended goals.

The open ended questions for the semi-structured interview and some of the responses from teachers are presented below.

\section{A. I can observe my own performance by/from...}

(1) “...comparing my lessons in different classes, at different times and levels. I try and see what is available for me from materials and audiovisual aids, etc., and how I can best make use of these. I regularly ask my students about my lessons, usually half-way through the course. Their feedback gives me some insight into how successful or less successful I am as a teacher." (A...)

(2) "I value the feedback from my students very much, and I pay attention to in-class observations." (C...)

(3) "I usually observe my performance by looking at the climate of the class and assessing interest levels of students." (Y...)

On the awareness of their students' needs and how they learn, the teachers emphasized on students' ways of thinking and having discussions with them before, during or after certain phases of the course. By valuing the student expectations, the teachers tend to change their teaching methodologies, as well.

\section{B. I'm aware of my students' needs and I know how they learn because...}

(1) ... understanding their way of thinking and having an idea about their backgrounds, I can best understand how to teach and encourage them to learn even on their own when they are away from school.” (A...) 
(2) "I hold a discussion at the beginning of the course with my students about their expectations of the course, and the methods and/or techniques they believe they can benefit most." (D...)

\section{I can always develop myself as a teacher because...}

(1) "I have to adapt to, or at least, take into consideration the latest (trends) in terms of teaching methods, as well as educational theories. "( $A$...)

\section{I am aware of my own belief as a teacher because...}

(1) “...success is achieved by self-confidence, and a strong belief in one's ability as a teacher and educator when you believe that the education process is an issue of learning and teaching at the same time."(A...)

(2) “...through the process of language teaching, I always try to have an unprejudiced and universal attitude towards my students as a teacher. I also try to encourage my students to gain similar ethic values." (S...)

The teachers further indicated that the teaching is a process through which they learn and develop themselves, too. They also suggest that having self-confidence and strong beliefs about their own abilities, exploring the insights of their capabilities, and knowing their won ethic values should be the main concern of educational process they go through.

\section{Conclusion and Discussion}

The present study mainly focused on the effect of three variables on reflective thinking: at various institutions, gender difference, and years of experience. The results were both analyzed quantitatively with statistical and frequency analysis and qualitatively through the content analysis of the semi-structured interview. First of all, differences among teachers from various institutions have been analyzed and both from the statistical analysis on one-way ANOVA test and the frequency analysis it is indicated that there is no statistically significant difference among teachers from various institutions (primary, secondary, university). It can be concluded that no matter what age groups teachers work with, they reflect on their own practice in a similar way.

Gender difference has been the second focus of the study and the only significant difference has been observed on male and female teachers. Through the independent-samples t-test results and the frequency analysis, it has been obtained that there is a scientifically significant difference between male and female teachers in terms of reflective thinking on their teaching practices. The frequency analysis on agree/strongly agree rates revealed that female teachers reflect on their practices with higher rates than their male colleagues. Thirdly, teachers' years of experience has been analyzed statistically and on a frequency analysis. The results show there is no scientifically significant difference among teachers with various years of experience although those at first years of their teaching practices rated slightly higher in general.

In addition to the quantitative analysis, a qualitative analysis was conducted through a semi-structured interview. Some of the teachers were asked to report on their reflective thinking through an inquiry form, which contained open ended questions on four major themes on the questionnaire, through email exchange. The interview inquiries reveal that teachers value feedback from their students, they do not consider their practice merely as teaching but also as a life-long learning, and they reflect on their own practices through several phases of the course According to Sezer (2008), in order to become reflective thinkers, the gap between learning situations can only be bridged through an awareness of what is known and what is needed. Unlike the results obtained by Choy and Oo (2012) with Malaysian teachers, who seemed to be more interested in maintaining their own perceived sense of self-worth and self-efficacy rather than using the comments by students as a means to help them improve, in the present study, teachers' statements on semi-structured interview form indicate that they have high metacognitive awareness of their own strengths and weaknesses, which according to Ball (2009) could help identify barriers to learning and changing strategies to attain goals. They even stated that they would change the way they teach in accordance with the feedback they obtain from their students.

Despite the ambiguity in its definition, on which there has not been a clear consensus, as Zeichner (2010) points out, reflection has been an international movement that developed in teaching and teacher education against the view of teachers as technicians who merely carry out what others, removed from the classroom want them to do, and of top-down approaches to educational reform that only involve teachers as passive participants. It is evident that reflective thinking on their own practices will contribute teachers with their professional 
development and make them active learners rather than passive teachers. On the other hand, only observing their rates on reflective thinking does not necessarily make them good or bad teachers, pre and post studies upon teachers' reflection on their practices could be conducted to clearly observe the reasons and results of it on teaching. Also, students' feedback upon teacher's reflection can be included into the research design, as the effect on them behold the primary concern of teaching.

\section{References}

[1] Ball, A. \& Lardner, T. (1997). Disposition Toward Literacy: Constructs of Teacher Knowledge and the Ann Arbor black English case. Paper presented at the conference on College Composition and Communication, Phoenix, Arizona.

[2] Bengtsson, J. (1993). Theory and Practice: Two fundamental categories in the philosophy of teacher education. In B, Wade, L. Davies, H. Thomas, G. Upton, M. Lawn, S. Walker, C. Chitty, \& D. Martin (Eds.), Educational Review 45(3). Abingdon: Carfax.

[3] Boody, R. M. (2008). Teacher Reflection as Teacher Change, and teacher change as moral response. Education, 128(3), 498-506.

[4] Borg, S. (2003). Teacher cognition in language teaching: A review of research on what language teachers think, know, believe, and do. Language Teaching, 36.2, 81-109.

http://dx.doi.org/10.1017/S0261444803001903

[5] Borg, S. (2006). Teacher cognition and language education: Research and practice. London: Continuum.

[6] Choy, S. C., \& P. S., (2012). Reflective thinking and teaching practices: A precursor for incorporating critical thinking into the classroom? International Journal of Instruction, 5(1) 1308-1407.

[7] Cohen, L., Manion, L., \& Morrison, K. (2000). Research Methods in Education (5th ed.). London: Routhledge. http://dx.doi.org/10.4324/9780203224342

[8] Dinkelman, T. (2003). Self-Study in Teacher Education: A means and ends tool for promoting reflective teaching. Journal of Teacher Education, 54(01), 6-18.

http://dx.doi.org/10.1177/0022487102238654

[9] Freeman, D. (2002). The hidden side of the work: Teacher knowledge and learning to teach: A perspective from North American educational research on teacher education in English language teaching. Language Teaching, 35(1), 1-13. http://dx.doi.org/10.1017/S0261444801001720

[10] Hamilton, S. J. (2005). Development in Reflective Thinking. In Choy, S. C., \& P. S., (2012). Reflective thinking and teaching practices: A precursor for incorporating critical thinking into the classroom? International Journal of Instruction, 5(1) 1308-1407.

[11] Markley, C. T., Miller, H., Kneeshaw, T., \& Herbert, B. E. (2009). The Relationship Between Instructors' Conceptions of Geosciences Learning and Classroom Practice at a Research University. Journal of Geosciences Education, 57(4), 264-274.

http://dx.doi.org/10.5408/1.3544276

[12] Martin Jr., R.E., Wood, G.H., \& Stevens, E.W. (1988). An Introduction to Teaching a Question of Commitment USA: Allyn and Bacon

[13] Minott, M.A. (2009) Reflection and Reflective Teaching, A Case study of Four Seasoned Teachers in the Cayman Islands. Germany: VDM Verlag Dr. Müller.

[14] Lucas, U., \& Tan, P. L. (2006, May). Assessing levels of reflective thinking: The evaluation of an instrument for use accounting and business education. Paper presented at the $1^{\text {st }}$ Pedagogic in Higher Education Conference, Liverpool Hope University, Liverpool.

[15] Pajares, M. F. (1992). Teachers' Beliefs and Educational Research: Clearing up a messy construct. Review of Educational Research, 62(3), 307-332.

http://dx.doi.org/10.3102/00346543062003307

[16] Radnor (2002). Researching Your Professional Practice: Doing interpretive research, doing qualitative research in educational settings. London: Open University Press.

[17] Schon, D. (1987). Educating the Reflective Practitioner. Paper presented at the meeting of the American Educational Research Association, Washington, DC. In Choy, S. C., \& P. S., (2012). Reflective thinking and teaching practices: A precursor for incorporating critical thinking into the classroom? International Journal of Instruction, 5(1) 1308-1407. 
[18] Tabachnick, B. R., and Zeichner, K. (1985). The development of teacher perspectives: Final report. Madison: University of Wisconsin, Wisconsin Center for Education Research. In Zeichner, K., \& Gore, J. (1990). Teacher socialization. W. Robert Houston (Ed.), Handbook of research on teacher education, 329-348. New York: Macmillan.

[19] Williams, M., \& Burden, R. (1997). Psychology for Language Teachers. London: Cambridge University Press. In Choy, S. C., \& P. S., (2012). Reflective thinking and teaching practices: A precursor for incorporating critical thinking into the classroom? International Journal of Instruction, 5(1) 1308-1407.

[20] Zeichner, K. \& Liu Y. (2010). A critical analysis of reflection as a goal for teacher education. In N. Lyons (Ed). Handbook of reflective inquiry. (pp. 67-84) New York: Springer.

http://dx.doi.org/10.1007/978-0-387-85744-2_4 